Original Research Paper

\title{
Study of Heavy Metals in the Surface Sediments of the Main Wadis in the Region of Meknes-Morocco
}

\author{
Lammini, A., A. Dehbi, H. Omari and A. Abdallaoui \\ Department of Chemistry, Analytical Chemistry and Environment Team, Faculty of Sciences, \\ Moulay Ismail University, PO Box 11201, Zitoune, Meknes, Morocco
}

\author{
Article history \\ Received: 12-12-2015 \\ Revised: 01-08-2015 \\ Accepted: 02-02-215 \\ Corresponding Author: \\ Abdallaoui, A. \\ Department of Chemistry, \\ Analytical Chemistry and \\ Environment Team, Faculty of \\ Sciences, Moulay Ismail \\ University, PO Box 11201, \\ Zitoune, Meknes, Morocco \\ Email: a.abdallaoui@gmail.com
}

\begin{abstract}
Because of their growing demographic and industrial expansion, the urban areas of the city of Meknes are likely to disturb the ecological balance of watercourse. In the present work, we had evaluate the degree of sediment's contamination by heavy metals ( $\mathrm{Al}, \mathrm{Cd}, \mathrm{Cu}, \mathrm{Fe}, \mathrm{Mn}, \mathrm{Pb}$ and $\mathrm{Zn}$ ) in the main wadis of the Meknes region (Boufekrane, Wislane and Toulal) which are tributaries of the oued R'doom. These heavy metals were assayed by ICP, after the sediment mineralization by aqua regia. Reference concentrations were determined by the method of coring. In parallel to this and for the characterization of the studied sediments, we also determined the physico-chemical parameters: Carbonates, organic matter, $\mathrm{pH}$ and granulometry. The analysis of the whole data collected by a multivariate statistical method (factorial correspondence analysis) allowed us to distinguish five groups of heavy metals.
\end{abstract}

Keywords: AFC, Watercourse, Heavy Metals, Pollution, Sediment

\section{Introduction}

The aquatic environment pollution has become one of the most serious nuisances, notably, that affects urban and industrial areas. The anthropic activities remain the main cause of the degradation of the quality of water in the surface: Wastewater discharges, agricultural activities notably the excessive use of fertilizers and pesticides.

However, the degree of pollution of the aquatic environment by heavy metals cannot always be evaluated only on the basis of their concentration in water. Indeed, on the one hand, the concentrations of heavy metals in the water are close to the detection levels limits where the uncertainty range is large enough. On the other hand, the heavy metals are subtracted from water by multiple processes and the concentrations consequently do not reflect the real significance of pollution owed to human activities, which accelerates the process of degradation of the quality of the wadis (Saadallah, 1991).

The analysis of metals in sediments appears to be a lane that allows circumventing these difficulties.

Elsewhere, the process of exchange of heavy metals at the water-sediment interface in particular, in relationship with adsorption and desorption equilibria, depend of the physicochemical parameters such as organic matter, carbonates, $\mathrm{pH}$ and the granulometry. For example an increase in $\mathrm{pH}$ promotes the adsorption of selected heavy metals on the reducible fraction of sediments (iron and manganese oxides), (Vanthuyne et al., 2003; Basta and Tabatabal, 1992a; 1992b; Kribi, 2005; Zhu and Alva, 1993; Tessier et al., 1990).

We therefore judged it important to determine the physicochemical parameters and evaluate metal concentrations of seven heavy metals; aluminum, cadmium, copper, iron, manganese, lead and zinc; of sediment deposited in the level of three main wadis of the Meknes region: Wislane, Boufekrane and Toulal.

\section{Materials and Methods}

\section{Study Sites}

The sites of our work are the Wadis of Wislane, Boufekrane and Toulal, which play an important socioeconomic role for the Region of Meknes; one of the most agricultural regions in Morocco.

Boufekrane Wadi is a permanent watercourse of the Sais plain. It flows through the lake basin of Meknes plateau, whose substratum consists of sandy limestone of Pliocène and its coverage (agricultural land) of Tertiary and Quaternary Age. It rises to the west of El Hajeb, in the Middle-Atas, $750 \mathrm{~m}$ above sea level (Saadallah, 1991). It holds the name of Aïn Maarouf near the source, then that of Boufekrane 10 $\mathrm{km}$ from it, until after its confluence in the first place 
with the Toulal wadi which crosses the Toulal commune and secondly with the Wadi Wislane (Fig. 1). The latter belongs to the superficial hydrographic network of the region of Meknès taking birth in the southeast of the Boufekrane village; the width of its watershed averaged 5-6 km. These streams cross the agricultural plain of the plateau of Meknes thus, they separate the agglomeration from city through the valleys. These three rivers meet downstream of the city of Meknes to form the Wadi R'Doom, which flows from the South to the North West with an average slope of 2 to $3 \%$, for to flow into in El Merja Jouab, north of Sidi Slimane, without joining the wadi Sebou (Saadallah, 1991).

\section{Samples Levies}

Sediment samples were taken using a plastic hand bucket, taking the precaution to take only the superficial part. This bucket often leads to a quite proper representativeness of the sample from the surface area $(3$ to $5 \mathrm{~cm}$ ).

The collected sediments were placed in plastic bags, transported in a cooler and processed within $24 \mathrm{~h}$. All sediments were sieved wet; after drying and soft grinding mortar to homogenize the sample less than 100 $\mu \mathrm{m}$ fractions were preserved for analysis.

As for the determination of concentrations of metals in sediment samples subjected to treatment prior to mineralization (Abdallaoui, 2013).

One gram of the fraction $<100 \mu \mathrm{m}$, in a $250 \mathrm{~mL}$ round bottom flask, we added $10 \mathrm{~mL}$ of aqua regia. The mixture was heated for 30 min under a condenser.

After cooling, rinsing of condenser, the supernatant is filtered through a $0.45 \mu \mathrm{m}$ membrane; the solution thus obtained is analyzed by ICP.

The solvent is prepared, at the same time, dealing with only $10 \mathrm{~mL}$ of aqua regia following the same procedure.

This method was used to measure heavy metals in sediments at the level of nine stations upstream and downstream the three wadis (Fig. 1 and Table 1). These samples were collected in three campaigns: April 2011, April 2012 and December 2012.

The results of our analyses of sediments from the nine stations (three campaigns averages \pm the standard deviation) are presented in Table 2 and Fig. 2.

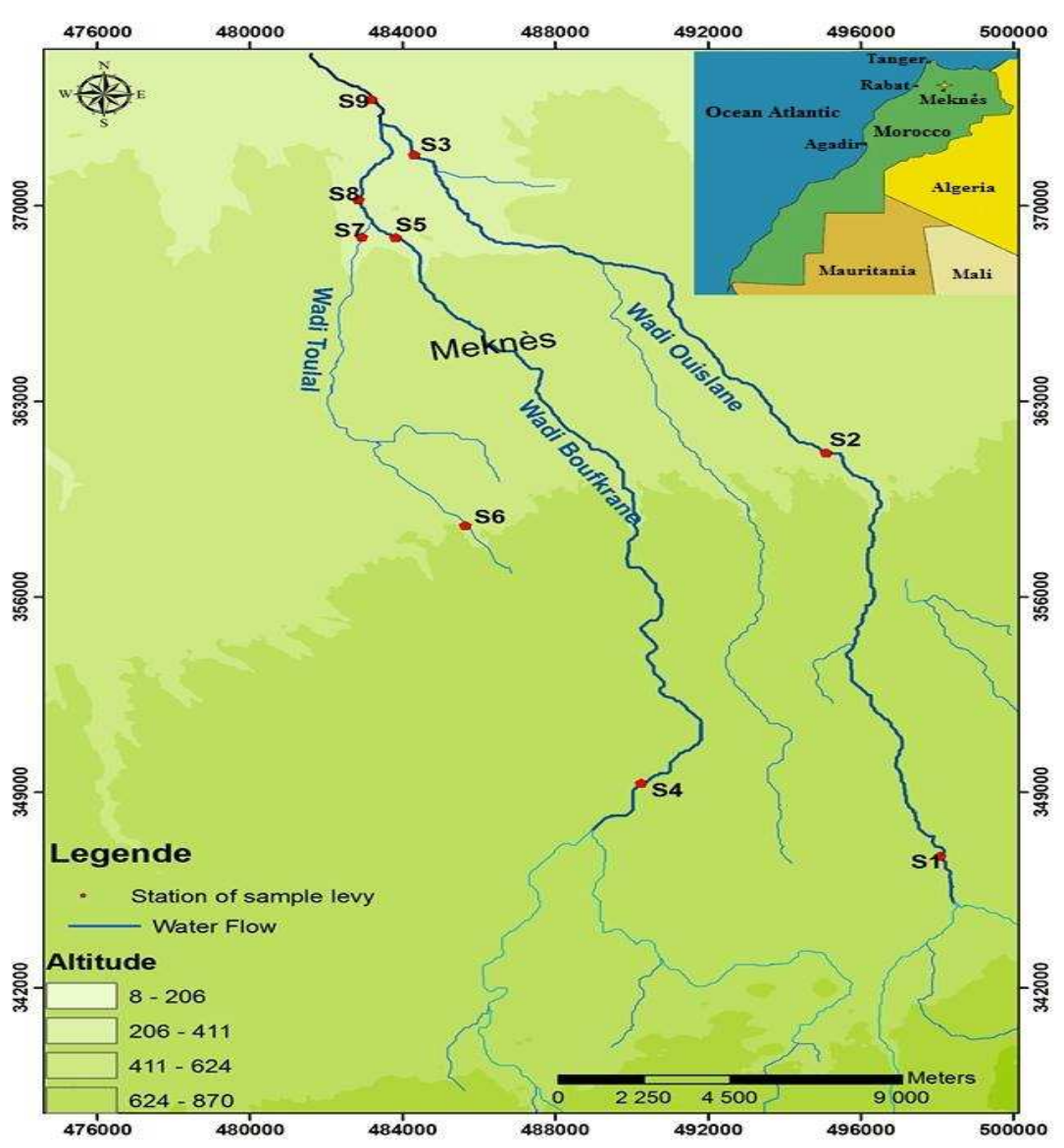

Fig. 1. Location of sampling stations 
Table 1. Nomination of stations and their location in relation to waterways

\begin{tabular}{lll}
\hline Stations & watercourse & Position in relation to watercourse \\
\hline S1 & Wislane & upstream \\
S2 & Wislane & in the Middle \\
S3 & Wislane & Just before the Confluence of the Wislane Wadi with the Boufekrane Wadi \\
S4 & Boufekrane & upstream \\
S5 & Boufekrane & Just before the confluence of Boufekrane Wadi and Toulal wadi \\
S6 & Toulal & upstream \\
S7 & Toulal & Just before the confluence of the Toulal Wadi and the Boufekrane Wadi \\
S8 & R'Doom & After the confluence of the Toulal Wadi and the Boufekrane Wadi \\
S9 & R'Doom & After the confluence of the Boufekrane and the Wislane Wadi \\
\hline
\end{tabular}

Table 2. Average and standard deviation $(\delta)$ of heavy metals content of sediments of the main watercourses of Meknes region, collected in April 2011, April 2012 and December 2012

\begin{tabular}{llllllll}
\hline Stations & $\mathrm{Al}(\mathrm{mg} / \mathrm{g}) \pm \delta$ & $\mathrm{Cd}(\mu \mathrm{g} / \mathrm{g}) \pm \delta$ & $\mathrm{Cu}(\mu \mathrm{g} / \mathrm{g}) \pm \delta$ & $\mathrm{Fe}(\mathrm{mg} / \mathrm{g}) \pm \delta$ & $\mathrm{Mn}(\mathrm{mg} / \mathrm{g}) \pm \delta$ & $\mathrm{Pb}(\mu \mathrm{g} / \mathrm{g}) \pm \delta$ & $\mathrm{Zn}(\mu \mathrm{g} / \mathrm{g}) \pm \delta$ \\
\hline S1 & $3.83 \pm 3.18$ & $2.60 \pm 0.10$ & $76.67 \pm 5.77$ & $23.50 \pm 5.63$ & $0.20 \pm 0.05$ & $18.50 \pm 2.78$ & $22.17 \pm 6.64$ \\
S2 & $4.35 \pm 2.44$ & $2.13 \pm 0.12$ & $36.67 \pm 7.02$ & $14.83 \pm 3.62$ & $0.13 \pm 0.02$ & $12.50 \pm 2.60$ & $15.83 \pm 5.25$ \\
S3 & $4.37 \pm 0.60$ & $2.10 \pm 0.10$ & $28.00 \pm 8.00$ & $12.50 \pm 3.04$ & $0.10 \pm 0.01$ & $19.17 \pm 4.07$ & $19.50 \pm 6.14$ \\
S4 & $2.35 \pm 1.21$ & $1.97 \pm 0.35$ & $18.67 \pm 8.14$ & $10.33 \pm 3.21$ & $0.22 \pm 0.07$ & $11.17 \pm 1.76$ & $11.83 \pm 2.93$ \\
S5 & $2.98 \pm 0.46$ & $1.63 \pm 0.32$ & $41.67 \pm 20.31$ & $6.83 \pm 0.58$ & $0.09 \pm 0.02$ & $86.67 \pm 20.21$ & $30.50 \pm 8.05$ \\
S6 & $4.23 \pm 2.19$ & $2.00 \pm 0.30$ & $17.17 \pm 7.29$ & $10.33 \pm 2.84$ & $0.15 \pm 0.06$ & $9.17 \pm 0.76$ & $7.83 \pm 2.25$ \\
S7 & $3.98 \pm 0.88$ & $1.73 \pm 0.21$ & $21.83 \pm 9.36$ & $9.50 \pm 1.00$ & $0.09 \pm 0.01$ & $20.67 \pm 5.51$ & $12.83 \pm 3.75$ \\
S8 & $4.08 \pm 0.58$ & $1.77 \pm 0.23$ & $21.33 \pm 7.57$ & $9.00 \pm 1.32$ & $0.08 \pm 0.01$ & $22.67 \pm 5.86$ & $14.00 \pm 3.61$ \\
S9 & $3.27 \pm 0.47$ & $1.80 \pm 0.35$ & $37.67 \pm 14.98$ & $9.50 \pm 3.12$ & $0.07 \pm 0.02$ & $20.83 \pm 6.60$ & $17.00 \pm 3.61$ \\
\hline
\end{tabular}

Table 3. Average of natural contents and standard deviation $(\delta)$ of heavy metals of sediments in the water courses of the Meknes region

\begin{tabular}{llllllll}
\hline Metals & $\mathrm{Al}(\mathrm{mg} / \mathrm{g}) \pm \delta$ & $\mathrm{Cd}(\mu \mathrm{g} / \mathrm{g}) \pm \delta$ & $\mathrm{Cu}(\mu \mathrm{g} / \mathrm{g}) \pm \delta$ & $\mathrm{Fe}(\mathrm{mg} / \mathrm{g}) \pm \delta$ & $\mathrm{Mn}(\mathrm{mg} / \mathrm{g}) \pm \delta$ & $\mathrm{Pb}(\mu \mathrm{g} / \mathrm{g}) \pm \delta$ & $\mathrm{Zn}(\mu \mathrm{g} / \mathrm{g}) \pm \delta$ \\
\hline Natural content & $2.82 \pm 0.81$ & $1.83 \pm 0.29$ & $27.83 \pm 12.34$ & $9.5 \pm 1.15$ & $0.15 \pm 0.03$ & $17.50 \pm 0.50$ & $8.83 \pm 0.76$ \\
\hline
\end{tabular}

Furthermore, physicochemical parameters (Table 3) were determined according to the following experimental protocols:

- Sediment pH: $10 \mathrm{~g}$ of crushed and dried sediment to which we add $25 \mathrm{~mL}$ of distilled water, were agitated for $2 \mathrm{~min}$. At least $30 \mathrm{~min}$ of decanting $\mathrm{pH}$ of supernatant is measured using a $\mathrm{pH}$ meter

- The organic content of the sediment was determined by differential weighing, after calcinations of $1 \mathrm{~g}$ of dry, crushed, sediment in the muffle oven at $550^{\circ} \mathrm{C}$ for $2 \mathrm{~h}$

- The determination of carbonate content was performed using calcimetre by Bernard. This to measure the percentage of $\mathrm{CaCO}_{3}$ in the sediment

- The fine ${ }^{2}$ fraction was separated from the sand fraction by washing on a sieve with mesh opening $63 \mu \mathrm{m}$

\section{Heavy Metals Studied}

Heavy metals examined as part of this study were chosen for several reasons, according to which we can categorize these metals into two groups.

\section{Group I}

Includes iron, manganese and aluminum: The choice of these metals was dictated by the fact that their oxides are one of the most important constituent phases of sediments (Saadallah, 1991). In addition, when these metals are in the presence of phosphorus, they form inorganic compounds, bioavailable for certain species of algae which proliferation promote the phenomenon of eutrophication of water bodies (Abdallaoui, 2013).

\section{Group II}

Includes zinc, lead, copper and cadmium: The choice of these metals was dictated by the fact that they are an index to the potential of the highest pollution and also of the fact that they are generally recognized as having the greatest impact on human health (OMS, 1980).

\section{Results and Discussion}

\section{Results}

The heavy metal concentrations in sediments depend on many physical, chemical, geographical lithological and anthropogenic parameters. This makes a better regional standard for the chosen watershed. This is unfortunately not the case in the study of metal pollution of the aqueous phase.

In the case of our wadis, the choice of standards has been made according to the core drilling method which is to choose points upstream to determine that the levels of metals in the deep part of the chosen 
forage were polluted. It is worth mentioning here that the depth of forage is $15 \mathrm{~cm}$.

This method seems very interesting since it considerably reduces the number of samples.

The results of measurements which represent the unpolluted sediment basins are cited as an average and standard deviation of three standard stations as shown below in Table 4 and Fig. 2.

Moreover, the theory of factorial correspondence analysis and its application in the field of the study of the environment allows to extract grouping results and to get graphical representation.

The results of the factorial correspondence analysis of the concentrations of heavy metals of sediments in the main wadis of Meknes are shown on Fig. 3, which represents the plane formed by the factorial axes F1 and F2. The Axis 1 explains $54.68 \%$ of the variance and the axis 2 explains $27.69 \%$ Both axes, thus, represent $82.37 \%$ of the inertia totality.

The method of factorial correspondence analysis that we have applied to our data aggregates the results into five classes of metals (Fig. 3).

\section{Lead}

According to The factorial analysis of correspondences, lead is present only in a Group (G1), different from the other groups. Indeed, the spatial variation of the concentration of lead, from one station to the other, is clearly different from those of other metals (Fig. 2).

Furthermore, the studied sediment of lead concentrations are averaged close to the natural content in all stations, except the station S5 where we found very high concentrations of lead, either $\left(86.67 \pm 20.21 \mathrm{mg}^{-\mathrm{g}^{-1}}\right)$,

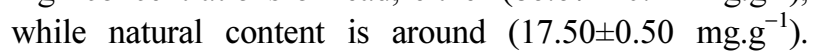
However, enrichment of sediments from the station S5 is probably due to releases of the brick-making units installed with the confluence of the Boufekrane River with Wadi Wislane. These industrial units probably use lead as a main product in their production.

\section{Copper and Zinc}

These two metals are a Group (G2) of the fact that their contents have the same spatial variations (Fig. 2). For zinc, we recorded well enrichment at levels of stations S1 $\left(22.17 \pm 6.64 \mu \mathrm{g} . \mathrm{g}^{-1}\right), \mathrm{S} 3\left(19.50 \pm 6.14 \mu \mathrm{g} \cdot \mathrm{g}^{-1}\right), \mathrm{S} 5$ $\left(30.50 \pm 8.05 \mu \mathrm{g} . \mathrm{g}^{-1}\right)$ and S9 $\left(17.00 \pm 3.61 \mu \mathrm{g} . \mathrm{g}^{-1}\right)$ compared to the content of the geochemical background $\left(8.83 \pm 0.76 \mu \mathrm{g} . \mathrm{g}^{-1}\right)$ registered in the region. This enrichment is probably due to the nature of the sediments studied containing high in organic matter and carbonate levels and more traffic has its direct impact on the pollution of aquatic sediments of the studied streams.

It should be noted that the station S5 has a concentration of $\left(30.50 \pm 8.05 \mu \mathrm{g} . \mathrm{g}^{-1}\right)$ and has a value almost three times the natural content $\left(8.83 \pm 0.76 \mu \mathrm{g} \cdot \mathrm{g}^{-1}\right)$, this high concentration is probably due to units of manufacture of bricks using zinc as basic elements installed in short distance from this station.

For copper, the contents registered in the sediments of all stations except station $\mathrm{S} 1$, are more or less close to the content of the geochemical background. However, the level of sediments from the station S1, we recorded content $\left(76.67 \pm 5.77 \mathrm{mg}^{-\mathrm{g}^{-1}}\right)$ that goes well beyond the reference content $\left(27.83 \pm 12.34 \mathrm{mg}^{-1} \mathrm{~g}^{-1}\right)$. The area of this station is characterized by lands where olive trees are cultivated, of which the result could be that farmers probably use copper as the main element in pesticides and fungicides, as copper sulphate solution.

\section{Aluminum}

This metal is characterized by levels that increase in average by the upstream to the downstream of Wadi Wislane from station $\mathrm{S} 1$ to station $\mathrm{S} 3$ and from upstream to downstream of the wadi Boufekrane, stations S4 to S6. This spatial variation relative to the levels of aluminum is unique compared to other metals. This explains the results of the factorial analysis of correspondences (Fig. 3), which have the metal in a different Group (G3) of the other studied metals groups.

Moreover, it is noted that concentrations of aluminum by sediments, ranged $\left(2.35 \pm 1.21 \mathrm{mg} . \mathrm{g}^{-1}\right)$ and $\left(4.37 \pm 0.60 \mathrm{mg} . \mathrm{g}^{-1}\right)$ and are on the whole more or less close to the natural value $\left(2.82 \pm 0.81 \mathrm{mg}^{-1} \mathrm{~g}^{-1}\right.$. Aluminium is an element found in nature. It is essentially linked to the structure of silicate minerals that are part of the main constituents of the sediment (Ben Bouih et al., 2005). It is widely used in the industrial field.

\section{Cadmium and Iron}

According to correspondence analysis, these two metals form a Group (G4) that their contents are almost the same spatial variations (Fig. 2). The results of this analysis show that the lead group G1 is located on the positive side of the axis F1, while cadmium and iron which form the group G4, are located on the negative side of this axis. Indeed, the spatial variation in lead content is significantly contrary to those of cadmium and iron (Fig. 2 and 3).

Furthermore, it is noted that the studied sediments are sufficiently rich in iron. For all samples analyzed in this study, iron is first class with plenty and its levels in most of the stations studied, do not exceed the natural levels, with the exception of sediments from the station S1. At this station, which is located upstream of the Wislane river, we recorded an enrichment of this metal. This enrichment is probably caused by the geological formation. 

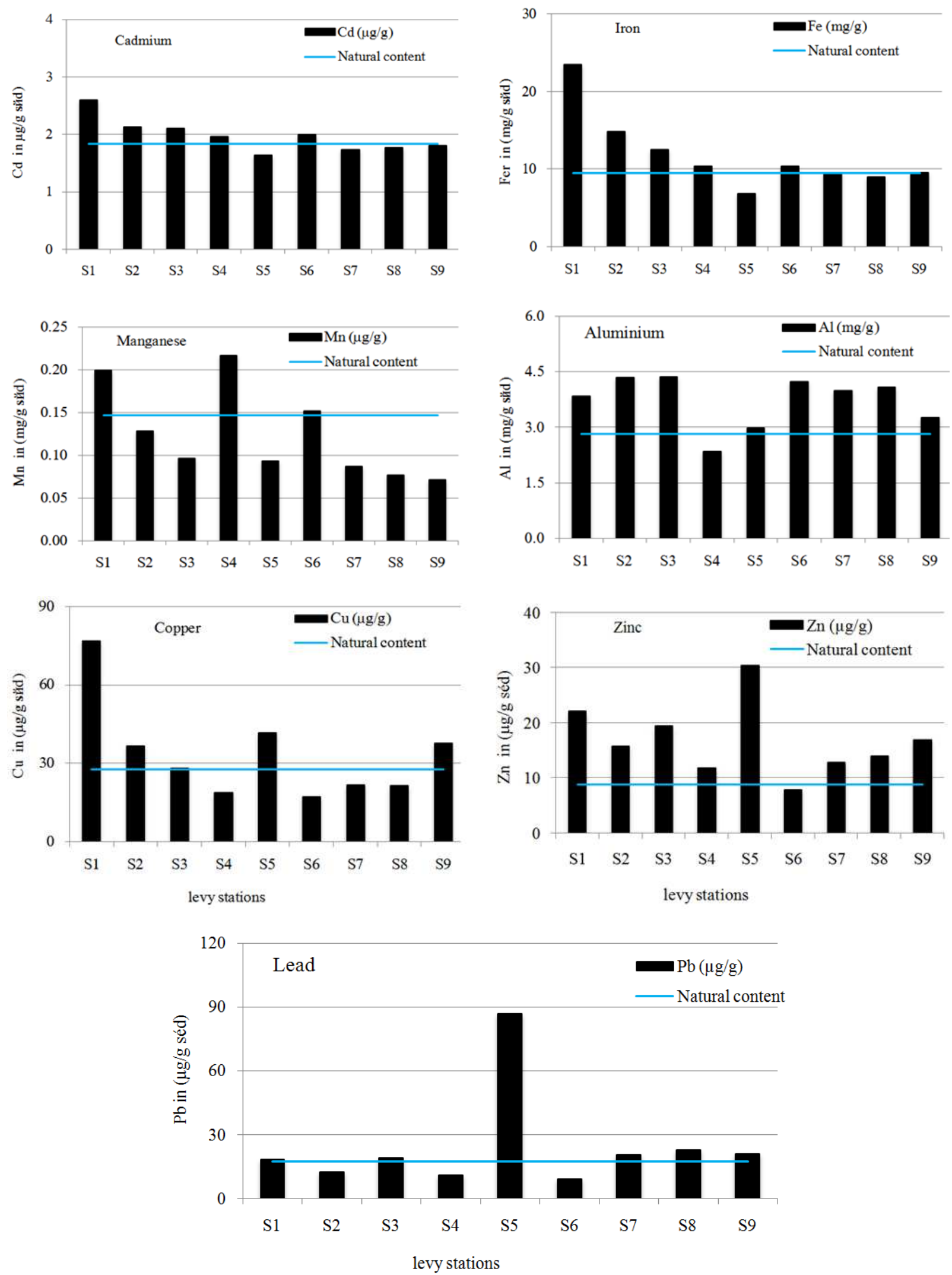

Fig. 2. Spatial variations of the concentrations of heavy metals of the studied sediments 


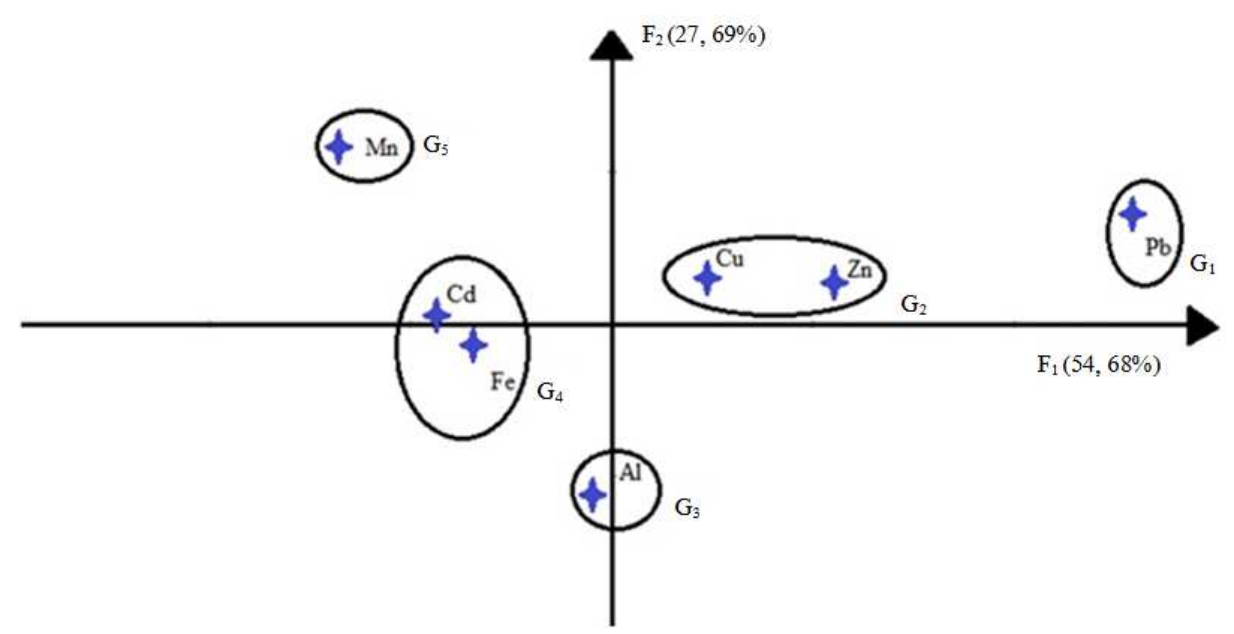

Fig. 3. Factorial analysis of correspondences of heavy metals of the studied sediments

Table 4. Physicochemical parameters of sediment from the water courses of the Meknes region expressed as average \pm standard deviation $(\delta)$

\begin{tabular}{lllll}
\hline Stations & $\mathrm{CaCO}_{3} \% \pm \delta$ & $\mathrm{MO} \% \pm \delta$ & $\mathrm{pH} \pm \delta$ & $\mathrm{FF}<63 \mu \mathrm{m} \% \pm \delta$ \\
\hline S1 & $39.76 \pm 0.9$ & $3.27 \pm 0.38$ & $7.75 \pm 0.25$ & $58 \pm 2$ \\
S2 & $28.52 \pm 4.4$ & $4.30 \pm 0.62$ & $8.11 \pm 0.26$ & $35 \pm 5$ \\
S3 & $28.84 \pm 5.0$ & $5.23 \pm 0.40$ & $8.12 \pm 0.11$ & $30 \pm 3$ \\
S4 & $40.89 \pm 3.1$ & $4.73 \pm 0.68$ & $7.74 \pm 0.21$ & $26 \pm 4$ \\
S5 & $28.47 \pm 8.8$ & $6.05 \pm 1.94$ & $8.25 \pm 0.31$ & $40 \pm 3$ \\
S6 & $34.74 \pm 10.8$ & $5.07 \pm 1.00$ & $7.84 \pm 0.13$ & $40 \pm 1$ \\
S7 & $32.48 \pm 2.4$ & $5.13 \pm 0.75$ & $8.23 \pm 0.15$ & $30 \pm 5$ \\
S8 & $23.93 \pm 10.0$ & $5.75 \pm 1.09$ & $8.34 \pm 0.41$ & $27 \pm 1$ \\
S9 & $33.00 \pm 4.1$ & $8.39 \pm 0.18$ & $24 \pm 2$ \\
\hline
\end{tabular}

\section{Manganese}

Manganese is unique compared to other metals studied according to correspondence analysis (Fig. 3). It presents the group G5, located to the negative side of the axis F1 and the positive side of the axis A2, different from other groups. Indeed, the variation of the concentration of this metal, from one station to the other, is clearly different from those of other metals (Fig. 2).

The manganese concentrations in the studied sediments vary between $\left(0.07 \pm 0.02 \quad \mathrm{mg} . \mathrm{g}^{-1}\right)$ and $\left(0.22 \pm 0.07 \mathrm{mg} . \mathrm{g}^{-1}\right)$. Overall these concentrations do not exhibit significant spatial variation. They are seen as close to the natural content determined by the core method $\left(0.15 \pm 0.03 \mathrm{mg} . \mathrm{g}^{-1}\right)$.

\section{Discussion}

Trade intensity of metallic water-sediment interface, depends on the environmental conditions . These can be natural, anthropogenic, atmospheric, solid or fluid. By studying the evolution of the concentrations in relation to the location of the samples, we notice that the studied metals have higher levels in sediment purposes, for example the sediment stations S1, S5 and S6 are up by the fine fraction $(<63$ microns), which represents more than $40 \%$.

Station S1 represents the maximum value FF $(58 \pm 2 \%)$, thate comprises the highest concentrations of metals in comparison with the stations S4, S8 and S9 which have a $30 \%$ of $\mathrm{FF}$ lower and illustrates the contents of the lowest metals. The size therefore seems to be the natural factor, the largest capable in varying the concentrations of heavy metals in the sediment. Additionally the grain sizes that make up sediment are, more able to fix the metals in the environment. Many authors have shown the relationships between the content of metallic element and the grain size of the sediment. The highest levels are found usually in the finest fraction of sediment. These results are in accordance with the work of (Abdallaoui, 2013; Yacoub et al., 2009; Coulibaly et al., 2009; Jaffe and Walters, 1977).

Thus there is a relationship between the rate of organic matter and heavy metal concentrations. This relationship can be explained by the important role of organic matter in the fixing and complexation of heavy metals in sediments. We noticed also at the station S5 that the organic matter seems responsible for the fixing of metals $\mathrm{Cu}, \mathrm{Pb}$ and $\mathrm{Zn}$ as it represents a high content is $(6.06 \pm 1.94 \%)$, or S6, upstream, which has almost the 
same rate of orgiastic material $(6.60 \pm 1.51 \%)$. Whereas S5 does not receive discharges that may contaminate the site. This result corroborates previous studies stating that metals are mainly related to the organic phase (Abdallaoui, 2013; Yacoub et al., 2009). Anthropogenic inputs, including domestic waste rich in organic matter, are of paramount importance and likely enter into the composition of the surface sediments in the study area.

Higher manganese concentrations of stations S1 and S4 are stored in the sediment having high carbonate contents. Indeed, we note that the carbonates formed an association with manganese.

According to Zerbe et al. (1999), in the sediment of an aquatic environment, the greater part of the manganese is bound to carbonate and likewise, in an aquatic environment, the lead sediment was mainly related to the hydrated oxide of iron.

Furthermore, in another river environment, Tessier et al. (1979) reported that in the largest amount of iron sediment was present in the residual fraction, particularly in the fraction bound to the oxides.

In addition, most metal contamination is anthropogenic. For example, a significant accumulation of zinc may be related to road traffic urban area (Bouras et al., 2010). These metals are then leached by rainwater to enrich wastewater these elements. Physical chemistry of the aquatic environment can influence the rate of fixation of metals by sediment.

The $\mathrm{pH}$, for example, is a major factor in the retention of metals because it controls all the processes affecting the behaviour of these elements. The change in $\mathrm{pH}$ (natural or anthropogenic) seems to be the factor whose action on metal mobility is most critical (Welte et al., 1983). A decrease in the value of the $\mathrm{pH}$ of the water supernatant also permits the release of these metals and their carbonate hydroxide (Abdallaoui, 2013).

\section{Conclusion}

The results presented in this study have allowed us to make an assessment of the concentration of heavy metal such as iron, manganese, aluminum, zinc, lead, copper and cadmium, as well as their spatial variations in sediments deposited in the upstream and downstream of the three wadis in Meknes.

These results showed that the levels of zinc are above normal in the studied locations in the stations S1, S3, S5 and S9, so there would likely be a source of those metallic elements from an urban area where there is an absence of any wastewater treatment and nonagricultural leaching of chemicals used. In addition to copper, zinc is also used in agriculture, knowing that polluted sites are around cultivated fields.

For iron, it is the first class in quantity and its levels in the most of the studied stations do not exceed natural levels, with the exception of the station located upstream of Wadi Wislane.the contamination by the metal is of natural origin.

On the other hand lead represents a single polluted station located downstream of the Boufekrane river. This contamination is particularly significant with a level five times higher than the natural content and it is probably due to the industrial brick field installed at the edge of the abovementioned area.

At the end, cadmium and manganese concentrations remain more or less stable and do not exceed natural levels.

\section{References}

Abdallaoui, A., 2013. Le phosphore et les métaux lourds contenus dans les sédiments: Leur influence sur les phénomènes d'eutrophisation et de pollution. 1st Edn., Éditions Universitaires Européennes, ISBN-10: 6131572429, pp: 348.

Basta, N.T and M.A. Tabatabal, 1992a. Effect of cropping Systems on adsorption of metals by soils: I. Single metal adsorption. Soil Sci., 153: 108-114. DOI: 10.1097/00010694-199202000-00004

Basta, N.T. and M.A. Tabatabal, 1992b. Effect of cropping Systems on adsorption of metals by soils: II. Effect of pH. Soil Sci., 153: 195-204.

Ben Bouih, H., H. Nassali, M. Leblans and A. Srhiri, 2005. Contamination en métaux traces des sédiments du lac Fouarat (Maroc). Afrique Sci., 1: 109-125.

Bouras, S., M. Maatoug, B. Hellal and N. Ayad, 2010. Quantification de la pollution des sols par le plomb et le zinc émis par le trafic routier (Cas de la ville de Sidi Bel Abbes, Algérie occidentale). Les Tech. De Laborat., 5: 11-17.

Coulibaly, A.S., S. MondE, V.A. Wognin and K. Aka, 2009. Analyse des Eléments Traces Métalliques (ETM) dans les baies estuariennes d'Abidjan en Côte d'ivoire. Afrique Sci., 05: 77-96.

Jaffe, D. and J.K. Walters, 1977. Intertidal trace metal concentrations in some sediments from the estuary. Sci., Total Environ. Am., 7: 1-15.

DOI: 10.1016/0048-9697(77)90012-2

Kribi, S., 2005. Décomposition des matières organiques et stabilisation des métaux lourds dans les sédiments de dragage. Thèse doctorat, Institut National des Sciences Appliquées de Lyon, pp: 220.

OMS, 1980. Les Micropolluants Dans Les Sédiments Fluviaux: Rapport Sur Une Réunion De l'OMS. Organisation Mondiale de la Santé, Bureau Régional de l'Europe, Copenhague, ISBN-10: 9289022272 , pp: 88.

Saadallah, M., 1991. Contribution à l'étude de la pollution métallique des sédiments des cous d'eaux Marocains-Cas de l'oued Boufekrane. Thèse de troisième cycle, Université Moulay Ismail, Faculté des Sciences Meknès, Maroc, pp: 182. 
Tessier, A., P.G. Campbell and M. Bisson, 1979. Sequential extraction procedure for the speciation of particulate trace metals. Anal. Chem., 51: 844-851. DOI: $10.1021 / \mathrm{ac} 50043 \mathrm{a} 017$

Tessier, A., P.G. Campbell and R. Carignan, 1990. Influence du $\mathrm{pH}$ sur la spéciation et la biodisponibilité des métaux. T.S.M.-L'EAU, 2: 69-73.

Vanthuyne, M., A. Maes and P. Cauwenberg, 2003. The use of flotation techniques in the remediation of heavy metal contaminated sediments and soils: An overview of controlling factors. Min. Eng., 16: 1131-1141. DOI: 10.1016/j.mineng.2003.06.012

Welte, B., N. Bles and A. Montiel, 1983. Etudes des différentes méthodes de spéciation des métaux lourds dans les sédiments II, applications. Environ. Technol. Let., 4: 223-238.
Yacoub, I., A.M. Kouassi, A.A. Adingra and J. Biemi, 2009. Concentration en métaux lourds des sédiments d'une lagune côtière tropicale: Lagune de Fresco (Côte d'Ivoire). J. Appl. Biosci., 18: 1009-1018.

Zerbe, J., T. Sobczynski, H. Elbanowska and J. Siepak, 1999. Speciation of heavy metals in bottom sediments of lakes. J. Polonaise Des Etudes Environ., 8: 331-339.

Zhu, B. and A.K. Alva, 1993. Differential adsorption of metals by soils as influenced by exchangeable cations and ionic strength. Soil Sci., 155: 61-66. DOI: 10.1097/00010694-199301000-00009. 